\title{
Prevalence of Urinary Tract Infections in Children and Changes in Sensitivity to Antibiotics of E. coli Strains
}

\author{
ADRIAN HASEGAN ${ }^{1,2}$, MARIA TOTAN ${ }^{1,3}$, ELISABETA ANTONESCU ${ }^{1,2}$, ADRIAN GHEORGHE BUMBU4*, CARMEN PANTIS4*, \\ CRISTIAN FURAU ${ }^{5,6}$, CRISTINA BARDACA (URDUCEA) ${ }^{7}$, NICOLAE GRIGORE ${ }^{1,2}$ \\ ${ }^{1}$ University of Sibiu, Faculty of Medicine, Department of Urology, 2-4 Corneliu Coposu, 550245, Sibiu, Romania \\ ${ }^{2}$ County Clinical Emergency Hospital, 2-4 Corneliu Coposu Blvd., 550245, Sibiu, Romania \\ ${ }^{3}$ Children's Hospital, 3 Gheorghe Baritiu Str., 550178, Sibiu, Romania \\ ${ }^{4}$ University of Oradea, Faculty of Medicine and Pharmacy, Department of Surgery, 101 Decembrie Sq., 410073, Oradea, Romania \\ ${ }^{5}$ Western University Vasile Goldis of Arad, Life Sciences Department, 94-96 Revolutiei Blvd., 310130, Arad, Romania \\ ${ }^{6}$ Arad County Clinical Hospital, Department of Obstetrics and Gynecology, Calea Victoriei, 310158, Arad, Romania \\ ${ }^{7}$ Politehnica University of Bucharest, Faculty of Applied Chemistry and Material Science, Analytical Chemistry and Environmental \\ Engineering Department,1-7 Gheorghe Polizu Str., 011061, Bucharest, Romania
}

\begin{abstract}
Urinary tract infections (UTIS) are the most common bacterial pathologies in children, but they are difficult to spot. The diagnosis relies on urine culture in order to measure the prevalence of the infection, to identify the etiology and the sensitivity of the germs to different antibiotics. Escherichia coli (E. coli) strains are the most common uro-pathogen germs. The change in sensitivity to antibiotic of these uro-pathogen bacteria should be closely monitored because the physicians should be informed about the evolution of the antibiotic resistance of $E$ coli, for a more effective treatment in their fight against diseases. The study aimed to determine the prevalence of UTIS and the evolution of antimicrobial sensitivity for $E$. coli. This retrospective study was performed over a period of 4 years, 2013-2016, and included all the patients admitted in the Children's Hospital, aged 0-18 years, with the suspicion of UTIs; also, the standard culture techniques for urine samples, the modified Kirby-Bauer disk diffusion method for the antibiotic sensitivity testing, and the disk diffusion method to confirm the ESBL production by the clinical isolates of E. coli in urine were used. The statistical analysis was performed using the proportions of sensitive, resistant and intermediates. Descriptive statistics like the total, mean and percentage were performed using the Statistical Package for the Social Sciences (SPSS), version 15.0 and Microsoft Excel. From 15389 urine cultures processed in 4 years, 1530 were positive (9.9\%). Among these positive urine cultures, 1056 (69\%) were positive for E. coli. Testing the E. coli to a range of antibiotics, according to CLSI standard, a high resistance to Ampicillin (69-96\%), Amoxicillin/Clavulanic acid (32-70\%), Trimethoprim/Sulfamethoxazole (36-42\%) was observed and low levels of resistance to Ceftazidime, Cefuroxime, Cefpodoxime, Gentamycin, Nalidixic acid. Among E. Coli strains, 9-9.6\% were ESBL positive. Despite the low number of positive urine cultures in a paediatric population, it is very important to perform the urine culture in order to correctly identify the etiology of UTIS, recommend the right antibiotic, and avoid the wrong use of the antibiotics in children.
\end{abstract}

Keywords: E. coli antibiotic resistance, UTI, children

Urinary tract infection (UTI) is among the most commonly encountered diseases [1] at all ages; anatomical changes in the urinary tract may be one of the causes [2]. In children they are one of the most common bacterial infections [3-5]. Up to 3-5\% of the girls and $1 \%$ of the boys will get at least one urinary infection by the age of $5[6,7]$, whereas the recurrence probability of the UTIs in children with urinary malformations is 40\% [6-9]. Sometimes the symptoms of these infections can be difficult to spot in kids. In infants and young children fever is sometimes the only symptom. In older children, low urinary symptoms (dysuria) may be the main symptom of UTI, or may be associated with cloudy, odorous urine $[10,11]$.

In order to determine the probability of an infection in a population with a high pre-test probability of infection, urine culture testing is required $[9,12]$. To identify the etiology of infection, first-line diagnosis is based on microbiological tests together with biochemical parameters, useful in exploring renal function for the diagnosis of acute, severe infections [13].

Urine culture is the gold standard for diagnosing UTI: greater than 50000 CFU (colony forming unit) on a catheterized specimen or suprapubic aspiration indicate presence of a UTI; greater than 100000 CFU on a voided specimen is considered a positive culture. This laboratory exam is a very important tool for the correct management of UTI because the percentage of positive urine cultures will measure the prevalence of the infection in paediatric population and will identify the etiology and the sensitivity of the germs to different antibiotics.

Accurate and timely diagnosis of these infections is important for determining appropriate treatment and preventing long-term complications such as renal injury, hypertension, and end-stage renal disease [14]. Proper and complete treatmenthelps complete recovery in mostcases of urinary infections. Children who have had urinary incontinence are more likely to have recurrent infections [6]. In order to have a proper diagnosis, we have to take care of the quality of urine sampling, the correct culturing, a proper identification of the germs involved and the correct interpretation of the results, respecting the reference limits, to obtain valuable information regarding the interpretation of the results [15-17]. Biochemical parameters are determined by modern procedures that ensure precise 
dosing/determination method in different pathologies, as well as in the urinary infectious cases [18-20].

The majority of cases of urinary tract infections are caused by Gram-negative bacteria [1]. E. Coli has the highest prevalence, followed by Klebsiella, Proteus, Enterobacter, Citrobacter, Staphylococcus saprophyticus and Enterococcus spp. [21].

The clinician needs a quick and accurate result, but the urine culture result with the identification of the uropathogen and its antibiotic sensitivity comes only after 48 hours, so he has to treat the patient in an empiric way, according to the statistics. As a consequence of the incorrect treatment, as well as of antibiotic abuse in children suspected of having urinary tract infection [22,23], the antimicrobial resistance became a major public health problem at global level with very significant consequences [24-26]. The fight against diseases also includes clinician's information on the most common aetiologies and the main risk factors involved in the disease, in the areas where they operate, for a more effective therapy [12].

The first objective of the study was to determine the prevalence of UTIs in the paediatric population, using the gold standard method, the positive urine culture and also to acknowledge the variation in time of the sensitivity to antibiotic for the most common uro-pathogen, the E. coli strains. Widespread use of antibiotics has led to the appearance of resistant microorganisms. As the sensitivity to antibiotic patterns of the microorganisms are frequently changing, this retrospective analysis was designed to assess the recent sensitivity to antibiotic pattern of $E$. coli in urinary tract infection and to determine the percentage of multi-resistance $E$. coli strains in the paediatric population.

\section{Experimental part}

\section{Material and method}

This study is a retrospective one on all the patients with ages between 0-18 years, admitted in the Children's Hospital from Sibiu, Romania, for a period of 4 years (20132016) with the clinical suspicion of UTI, where the paediatrician asked for a urine culture. The data set contains information on 15389 clinical data collected in this period. The laboratory used the standard culture techniques for urine samples and evaluated the results of positive urine cultures.

Positive culture in infants and children is defined as a single pathogen growth in cultures in an amount $>10^{5} \mathrm{CFU} /$ $\mathrm{mL}$. All the urine cultures with two or more uro-pathogenic growth were excluded from the analysis and reported as contaminated samples due to incorrect collection (commonly found in infants and young children). For quantitative urine cultivation (to confirm the UTI diagnosis)

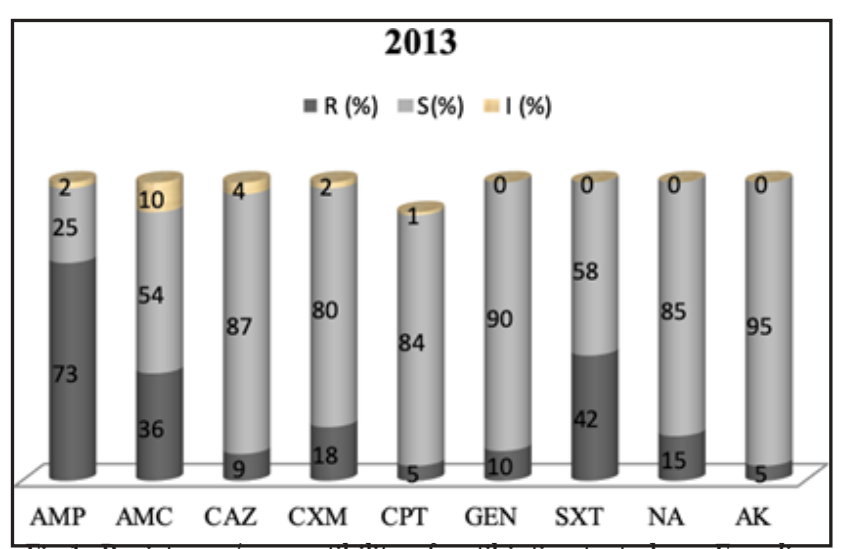

Fig.1. Resistance/susceptiblitity of antibiotics tested on E. coll

in 2013 the urine sample was seeded with $1 \mu \mathrm{L}$ strain, on a culture medium (chromogenic medium), incubated at $37^{\circ} \mathrm{C}$, for 18-24 h.

Antibiograms were performed in all isolates to determine the antibiotic sensitivity, using the modified Kirby-Bauer disk diffusion method, on Mueller-Hinton medium. Following an incubation at $37^{\circ} \mathrm{C}$, for $18-24 \mathrm{~h}$, the diameters of inhibition zones (IZ) were determined in millimetres. The antibiotics tested for sensitivity were Ampicillin $10 \mu \mathrm{g}$, Amoxicillin/Clavulanic acid $30 \mu \mathrm{g}$, Ceftazidime $10 \mu \mathrm{g}$, Cefuroxime $30 \mu \mathrm{g}$, Cefpodoxime $10 \mu \mathrm{g}$, Gentamycin 10 $\mu \mathrm{g}$, Sulfamethoxazole/Trimethoprim $25 \mu \mathrm{g}$, and Nalidixic acid $30 \mu \mathrm{g}$.

The CLSI 2017 guide was used to interpret the results (sensitivity/resistance/intermediates). The diffusion disc method was used to detect ESBL-producing strains, to highlight the synergism between amoxicillin/clavulanic acid/ceftazidime. E. coli being the most common germ in the UTIs, our research studied its sensitivity/resistance to antibiotics, depending on the year of testing (2013-2016).

\section{Statistics}

Descriptive statistics like the total, mean and percentage were done by using the Statistical Package for the Social Sciences (SPSS), version 15.0. For arranging the data, Microsoft Excel was used.

\section{Results and discussions}

From the 15389 urine cultures processed, 1530 positive cultures (9.9\%) were found. Analysing the type of bacteria identified in the positive urine cultures, $E$. colistrains were found in 1056 urine cultures (69\%), so most of the etiological agents of UTIs were $E$. coli strains. In these circumstances, $E$. coli was found to be the most common bacterial uro-pathogen that caused UTIs in infants and children, a conclusion revealed by other studies as well [16]. The rest of positive urine cultures were tested to determine the sensitivity/resistance to a series of antibiotics, being positive with other germs.

In 2013, in terms of antibiotic sensitivity/resistance, $E$. coli cultures showed (Fig. 1) very high resistance to Ampicillin (73\%), Sulfamethoxazole/ Trimethoprim (42\%) and Amoxicillin/Clavulanic acid (36\%), and high levels of sensitivity to cephalosporins (Ceftazidime 92\%, Cefpodoxime $84 \%$, Cefuroxime $80 \%$ ), Gentamycin $90 \%$ and Nalidixic acid $85 \%$.

Analysing the antibiotic resistance/ susceptibility in 2014 (Figure 2), we observed a significant increase in Ampicillin resistance $(96 \%)$, with a small decrease in Sulfamethoxazole/ Trimethoprim (39\%) and Amoxicillin/ Clavulanic Acid resistance (32\%). The susceptibility for cephalosporins was about the same: (Ceftazidime 87\%,

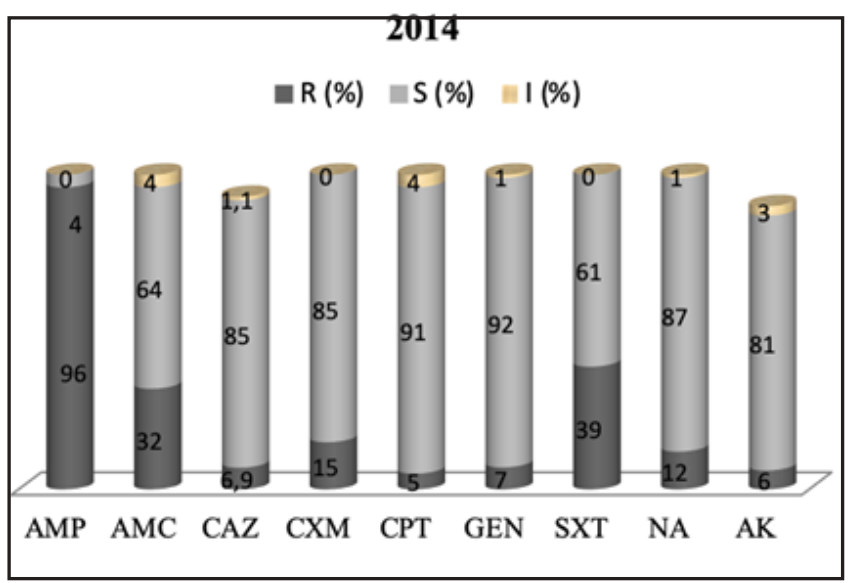

Fig.2. Resistance/susceptibility of antibiotics tested on E. coli in 2014 
Cefuroxime $85 \%$, Cefpodoxime 91\%), Gentamycin 92\% and Nalidixic Acid $87 \%$.

Analysing the antibiotic resistance/sensitivity in 2015 we observed a significant decrease in ampicillin resistance (71\%), with a significant increase in Amoxicillin/Clavulanic Acid resistance $(70 \%)$ and a small decrease in Sulfamethoxazole /Trimethoprim resistance (36\%). The sensitivity for cephalosporins was about the same: Ceftazidime $87 \%$, Cefuroxime $87 \%$, Cefpodoxime 93\% Gentamycin $86 \%$ and Nalidixic acid $85 \%$ (Figure 3).

In 2016, in terms of antibiotic resistance/sensitivity, $E$. coli cultures showed a decrease in Ampicillin resistance (69\%), in Amoxicillin/Clavulanic acid resistance (36\%) and a small increase in Sulfamethoxazole/Trimethoprim resistance $(41 \%)$. The sensitivity for cephalosporins (Ceftazidime $85 \%$, Cefuroxime $87 \%$, Cefpodoxime 92\%), Gentamycin $92 \%$ and Nalidixic acid $87 \%$ did not change significantly (Figure 4).

According to our antibiogram results, $9 \%$ of $E$. colistrains are ESBL positive in 2013, with an increased number in 2014 to $9.6 \%$, with a small decrease (to $9.4 \%$ ) in 2015 , and with another increase to $9.6 \%$ in 2016 (Figure 5), so there are not considerable changes in the percentages of multiresistant $E$. coli strains during these 4 years.

The data analysis revealed that $E$. coli strains (ESBL positive) were sensitive to Gentamycin and Nalidixic acid. The resistance/sensibility of $E$. coli strains during these 4 years was analysed (Table 1 ) and the very high sensitivity (above 80\%) for cephalosporins, Gentamycin, and Nalidixic acid was noticed.

The lowest susceptibility was observed for Ampicillin (between $25 \%$ and $31 \%$ ), with a very low value in 2014 (4\%). For Amoxicillin/ Clavulanic acid, the susceptibility varies between $54 \%$ and $64 \%$, so about half of the $E$. coli are susceptible/resistant to this antibiotic. For Sulfamethoxazole /Trimethoprim more than half of E. coli strains are sensitive (between 58\% and 64\%) (Figure 6).
Usually, urinary infections should be targeted treated by administering an antibiotic to which the infectious germ is sensitive, as evidenced by urocultures and antibiograms. In the case of general condition being altered - fever, chills, etc. (urinary sepsis), broad-spectrum antibiotic treatment is started, until uroculture results are obtained, after which the antibiotic is changed according to the antibiogram. During this period, patients receive hydro-electrolytic and haemodynamic rebalancing treatment. After treatment and restoration of the patient's well-being, if the infection recurs (after its apparent cure), with the alteration of the general condition, a favourable cause of the urinary tract infection should be considered. In such situations, the doctor recommends an investigational protocol specific to the type of symptomatology. For example, in the case of vesical-ureteral reflux, retrograde and micturition cystography (exploration of choice for the diagnosis of vesical-ureteral reflux); urinal echography (in the case of a possible congenital megaureter); urography (in the diagnosis of a possible pyelo-ureteral junction syndrome or congenital ureteral valves); renal scintigraphy (shows renal function and should be done in case of an allergy to iodinated contrast substance or to support the indication of nephrectomy, where urography does not indicate this) etc. may be performed (Figures 7-9).

Some studies have shown that the antibiotics used in UTIs treatment have as side effects the destruction of normal flora and the increase of micro-organisms resistance to certain antibiotics, these effects becoming a global problem $[27,28]$. In order to restore the intestinal flora [29-31] and to increase the resistance of the organism to UTIs, it is necessary to administer probiotics and antioxidants (as ascorbic acid) during or after the antibiotic treatment [32-34], this being proved a beneficial and effective solution in the prophylaxis and treatment of UTI $[27,28]$. The literature mentions that probiotics, administered as monotherapy during the UTIs, without an antibiotic, did not have significant benefits on prevention

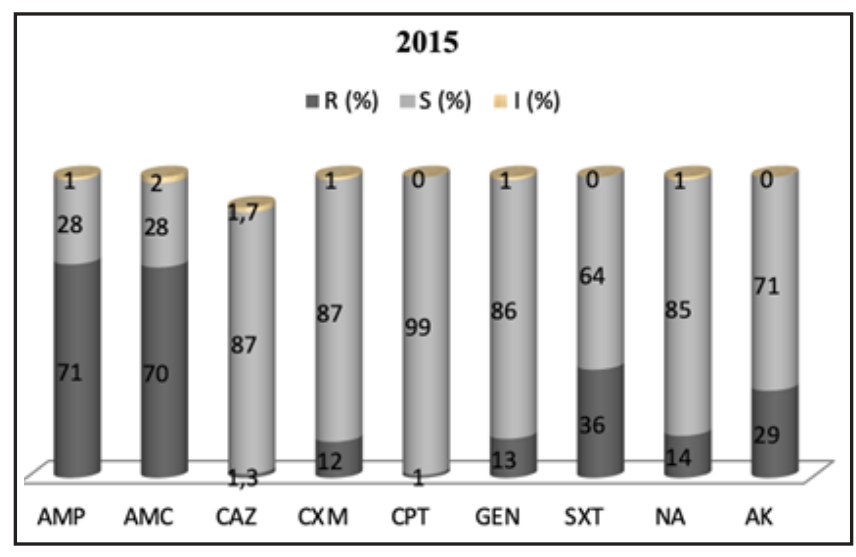

Fig.3. Resistance/susceptibility of antibiotics tested on E. coli in 2015

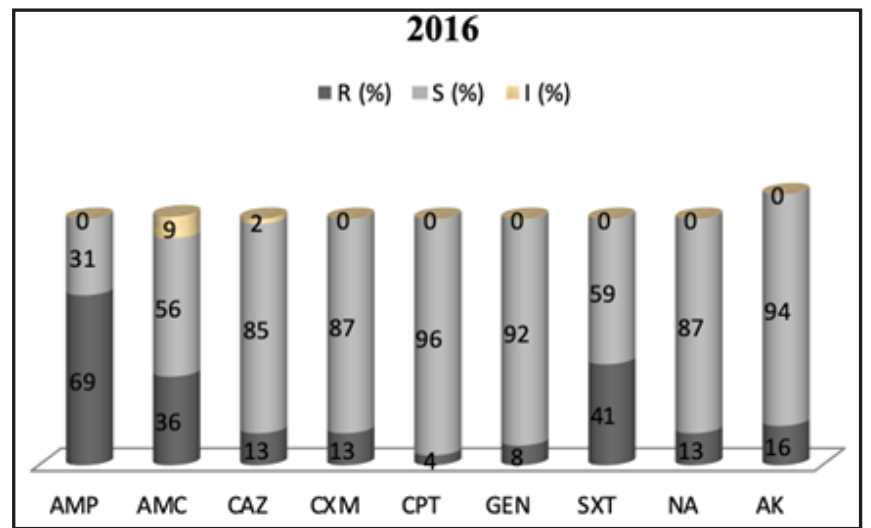

Fig.4. Resistance/susceptibility of antibiotics tested on E. coli in
2016

http://www.revistadechimie.ro

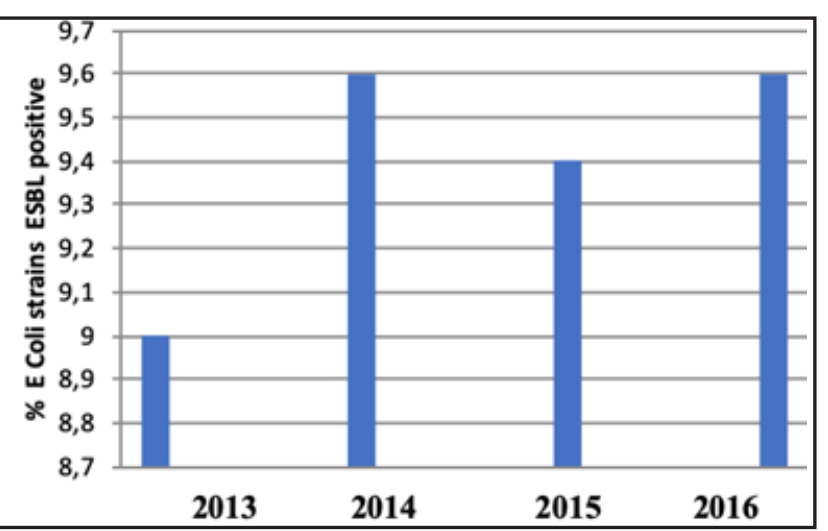

Fig.5. E. coli strains, ESBL positive

REV.CHIM.(Bucharest) 70 No. 11 \2019 
Table 1

ANTIBIOTIC RESISTANCE PROFILES OF CLINICAL ISOLATES BETWEEN YEARS 2013-2016

\begin{tabular}{|c|c|c|c|c|c|c|c|c|c|c|c|c|c|}
\hline The isolated strain & \multicolumn{13}{|c|}{ E. coli } \\
\hline \multirow{3}{*}{ Antibiotic } & \multirow{3}{*}{$\begin{array}{l}\text { Dose } \\
(\mu \mathrm{L})\end{array}$} & \multicolumn{3}{|c|}{2013} & \multicolumn{3}{|c|}{2014} & \multicolumn{3}{|c|}{2015} & \multicolumn{3}{|c|}{2016} \\
\hline & & $\mathrm{R}$ & $\mathrm{S}$ & I & $\mathrm{R}$ & $\mathrm{S}$ & I & $\mathrm{R}$ & $\mathrm{S}$ & I & $\mathrm{R}$ & $\mathrm{S}$ & I \\
\hline & & \multicolumn{12}{|c|}{$\%$} \\
\hline Ampicillin & 10 & 73 & 25 & 2 & 96 & 4 & - & 71 & 28 & 1 & 69 & 31 & - \\
\hline $\begin{array}{l}\text { Amoxicillin } \\
\text { clavulanic acid }\end{array}$ & 30 & 36 & 54 & 10 & 32 & 64 & 4 & 70 & 28 & 2 & 36 & 56 & 9 \\
\hline Ceftazidime & 10 & 9 & 87 & 4 & 69 & 92 & 1.1 & 11.3 & 87 & 1.7 & 13 & 85 & 2 \\
\hline Cefuroxime & 30 & 18 & 80 & 2 & 15 & 85 & - & 12 & 87 & 1 & 13 & 87 & - \\
\hline Cefpodoxime & 10 & 5 & 84 & 1 & 5 & 91 & 4 & 7 & 93 & - & 8 & 92 & - \\
\hline Gentamycin & 10 & 10 & 90 & - & 7 & 92 & 1 & 13 & 86 & 1 & 8 & 92 & - \\
\hline $\begin{array}{l}\text { Sulfamethoxazole } \\
\text { /Trimethoprim }\end{array}$ & 25 & 42 & 58 & - & 39 & 61 & - & 36 & 64 & - & 41 & 59 & - \\
\hline Nalidixic acid & 30 & 15 & 85 & - & 12 & 87 & 1 & 14 & 85 & 1 & 13 & 87 & - \\
\hline \multicolumn{2}{|l|}{ ESBL + } & \multicolumn{3}{|c|}{9} & \multicolumn{3}{|c|}{9.6} & \multicolumn{3}{|c|}{9.4} & \multicolumn{3}{|c|}{9.6} \\
\hline
\end{tabular}

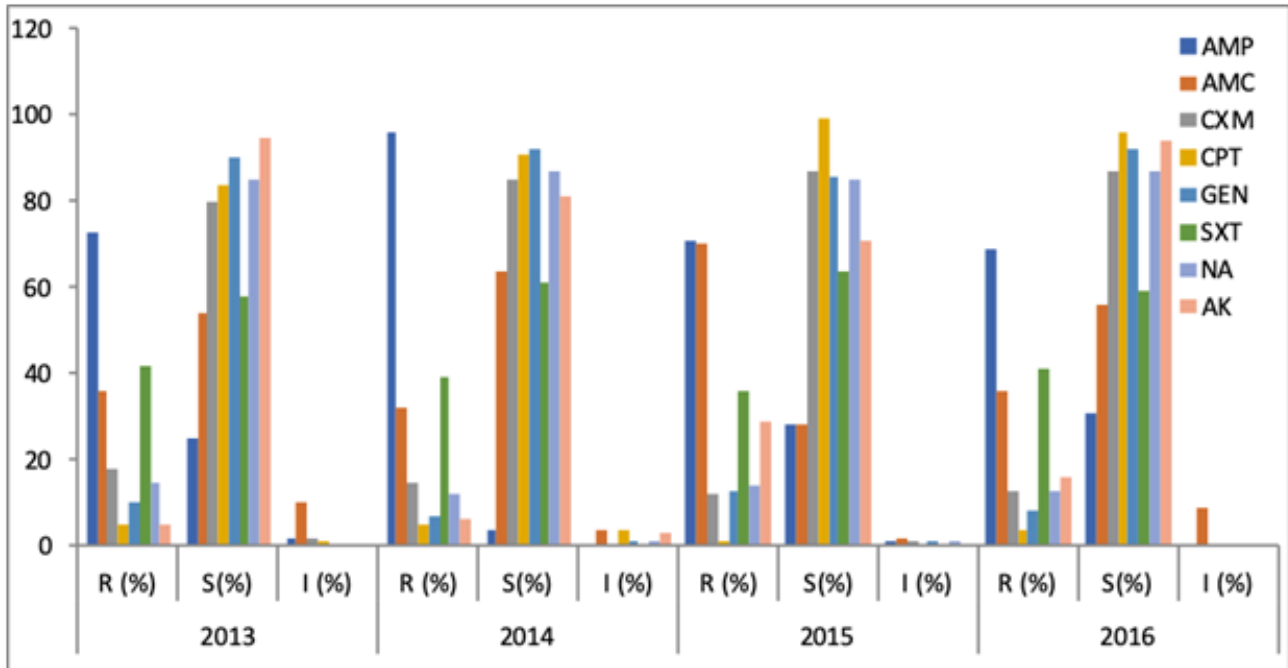

Fig.6. Resistance/susceptibility/ intermediate of tested $E$. coli strains to antibiotics ( $R$ : Resistance; S: Susceptibility; I: Intermediate)

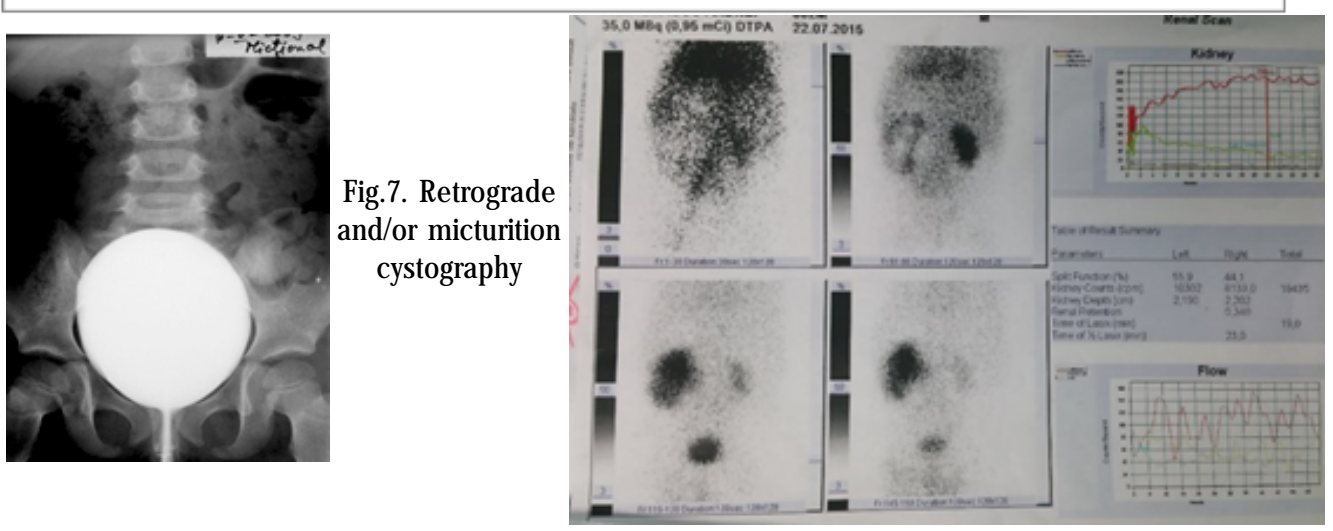

Fig.8. Kidney scintigraphy

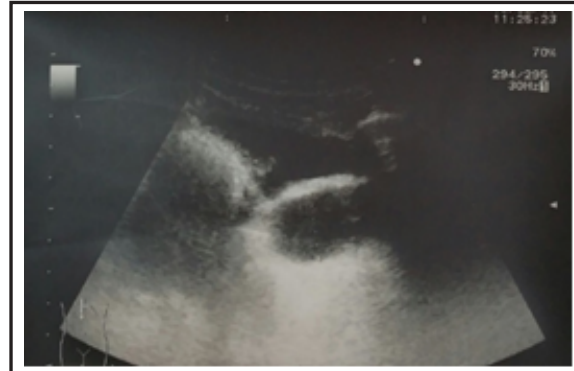

a.

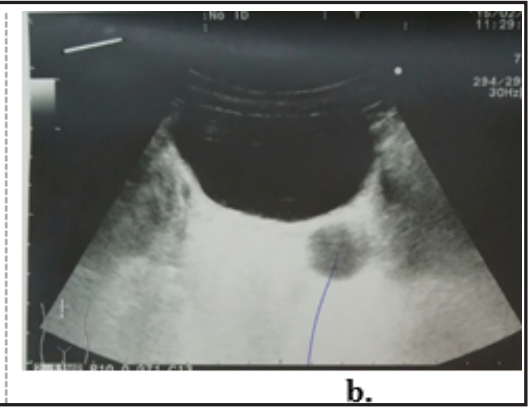

\section{Conclusions}

UTIs are not very common diseases among children (only $9.9 \%$ of the tested urines were positive). The large number of negative uro-cultures is explained by the fact that paediatricians are asking for uro-culture to evaluate febrile syndrome, a frequent entity in paediatric pathology. Similar to other studies in the literature, our results obtained 
on the aetiology of UTI revealed that $E$. coli was the most frequently isolated bacterium. The isolated strains had good sensitivity to Nalidixic acid and Gentamicin. As well, E. coli has been shown to have high resistance against commonly used antibiotics such as Ampicillin, Amoxicillin and Trimethoprim/Sulfamethoxazole. Therefore, it is essential to determine the etiologic pathogens that cause UTI and subsequently determine their sensitivity to antibiotics to help physicians determine the most appropriate choice of antibiotic treatment.

Acknowledgements. We would like to express our special thanks to Professor Simona Bungau and Professor Gheorghe Bumbu, University of Oradea and Associate Professor Ovidiu Gabriel Bratu, University of Medicine and Pharmacy Carol Davila for their contribution to the improvement of this work and the personal archive images (Professor G. Bumbu).

Ethical statement. This study, being a retrospective one, did not required a written consent of the involved patients.

\section{References}

1.GRIGORE, N., TOTAN, M., PIRVUT, V., et al., Rev. Chim. (Bucharest), 68, nr. 7, 2017, p.1453.

2.BUMBU, A., PASCA, B., TIT, D. M., BUNGAU, S., BUMBU, G., Farmacia, 64, nr. 3, 2016, p. 419.

3.SIMOES, A.C., Oliveira, E. A., J. Pediatria, 91, nr. 6, 2015, p. S2. 4.MANDAL, J., EMJ Urol., 4, nr. 1, 2016, p.101.

5.BUMBU, B., NACER, K., BRATU, O., BERECHET, M., BUMBU, G, BUMBU, A., Proceedings of the 14th National Congress of Urogynecology and the National Conference of the Romanian Association for the Study of Pain, 2017, p. 90.

6.GUNASEKERA, V., Sri Lanka J. Child Health, 39, nr. 3, 2010, p.104.

7.NOR, N.S.M., ABU, N.A., RASHID, M.A., FADZLI, F.M., ISMAIL M.M., et al., Med. J. Malaysia, 70, nr. 3, 2015, p.153.

8.MAHYAR, A., AYAZI, P., GHOLMOHAMMADI, P., MOSHIRI, S. A., OVEISI, S., ESMAEILY, S., Le Infezioni in Medicina, 1, 2016, p. 38.

9.RENDA, R., Int. J. Pediatr., 6, nr. 1, 2018, p.6815.

10.BUMBU, A., NACER, K., BRATU, O., BERECHET, M., BUMBU, G., BUMBU, B., Proceedings of the 14th National Congress of Urogynecology and the National Conference of the Romanian Association for the Study of Pain, 2017, p. 82.

11.AYAZI, P., MAHYAR, A., JAHANI, H. H., KHABIRI, S, Iran. J. Pediatr. Soc, 2, nr. 1, 2010, p. 9.

12.SHAIKH, N., MORONE, N. E., BOST, J. E., FARRELL, M. H., Pediatric infectious Disease J., 27, nr. 4, 2008, p. 302.

13.GRIGORE, N., PIRVUT, V., TOTAN, M., et al., Rev. Chim. (Bucharest), 68, no.6, 2017, p.1285.

14.J ACOBSONS, H.J, EKLOF, O., ERIKSSON, C.G., et al., BMJ , 299, nr. 6701,1989, p.703.

15.TOTAN, M., GLIGOR, F.G., BOJITA, M., GRIGORE, C., GRIGORE, C., Rom. Rev. Lab. Med., 21, nr. 1, 2013, p. 39.
16.COLANTONIO, D. A., KYRIAKOPOULOU, L., CHAN, M. K., DALY, C. H., BRINC, D., VENNER, A. A., et al, CLIN. CHEM., 58, nr. 5, 2012, p. 854.

17.ANTONESCU, E., BOTA, G., SERB, B., ATASIE, D., TATARU-DAHM, C., TOTAN, M., DUICA, L., SILISTEANU, S.C., SZAKACS, J., ARGHIR, O.C., OSWALD, I., MANEA, M. M., Rev. Chim. (Bucharest), 69, no. 12, 2018, p. 3389.

18.CHU, C. M., LOWDER, J. L., Am. J. Obst. Gynecol., 219, nr. 1, 2018, p. 40.

19.TOTAN, M., ANTONESCU, E., GLIGOR, F.G., Indian J. Pharm.Sci., 80, nr. 2, 2018, p. 268.

20.PALLAG, A., ROSCA, E., TIT, D.M., MUTIU, G., BUNGAU, S.G., POP,

O.L., Rom. J. Morphol. Embriol., 56, nr. 3, 2015, p. 1103.

21.SHAIKH, N., MORONE, N.E., LOPEZ, J., et al., JAMA, 298, nr. 24, 2007, p. 2895.

22.MENGISTU, A., FORSTER, N., GAESEB, J ., et al., Pharmacovig. Drug Safety, 1, nr. 1, 2014, p. 1.

23.RAY, J., PAUL, R., HALDAR, A., MONDOL, S., Int. J. Med. Sci. Public Health, 4, nr. 12, 2015, p.1670.

24.GOOSSENS, H., FERECH, M., STICHELE, R.V., ELSEVIERS, M., Lancet, 365,2005, p. 579.

25.ODSBU, I., KHEDKAR, S., LIND, F., et al., Int. J. Environ. Res. Public Health, 15, nr. 155, 2018.

26.MITACHE, M. M., CURUTIU, C., RUSU, E., BAHNA, R., DITU, M., MOLDOVAN, H., HANCU, V., CHIFIRIUC, M. C., Rev. Chim. (Bucharest), 68, nr. 3, 2017, p. 566.

27.BRYCE, A., HAY, A. D., LANE, I. F., et al., BMJ, 352, nr. i939, 2016. 28.MOHSENI, M. J., ARYAN, Z., EMAMZADEH-FARD, S., PAYDARY, K., MOFID, V., et al., Iran J. Pediatr., 23, nr. 4, 2013, p.430.

29.TOTAN, M., ANTONESCU, E., GRIGORE, N., et al., Rev. Chim. (Bucharest), 68, no. 6, 2017, p. 1264.

30.RADULESCU, A., MADAN, V., AUNGURENCI, A., BRATU, O., FARCAS, C., DINU, M., MISCHIANU, D., Rom. J. Mil. Med., 118, nr. 3, 2015, p. 20. 31.SPINU, D., BRATU, O., POPESCU, R., MARCU, D., RADULESCU, A., MISCHIANU, D., Rom. J. Mil. Med., 118, nr. 3, 2015, p. 12.

32.HEMPEL, S., NEWBERRY, S. J., MAHER, A. R., et al., JAMA, 307, nr. 18, 2012, p. 1959.

33.ABDEL-DAIM, M.M., ABO-EL-SOOUD, K., ALEYA, L., BUNGAU, S.G., NAJDA, A., SALUJA, R., Oxid. Med. Cell. Longev., 2018, ID 6276438, 2018 https://doi.org/10.1155/2018/6276438

34.ABDEL-DAIM, M.M., ZAKHARY, N.I., ALEYA, L., BUNGAU, S.G., BOHARA, R.A., SIDDIQI, N.J., Oxid. Med. Cell. Longev., 2018, ID 2098123, 2018 https://doi.org/10.1155/2018/2098123

35.ABDEL-DAIM, M.M., ALEYA, L., EL-BIALY, B.E., ABUSHOUK A.I., ALKAHTANI, S., et al., Environ. Sci. Pollut. Res., 2019 http://dx.doi.org/ 10.1007/s11356-019-04801-2

36.ABDEL-DAIM, M.M., ABUSHOUK, A.I., DONIA, T., ALARIFI, S., ALKAHTANI, S., et al., Environ. Sci. Pollut. Res., 2019 http://dx.doi.org/ 10.1007/s11356-019-04780-4

37.ABDEL-DAIM, M.M., AHMED, A., IJ AZ, J., ABUSHOUK, A.I., AHMED, H., NEGIDA, A., et al., Environ. Sci. Pollut. Res., 26, nr. 8, 2019, p. 8080. https://doi.org/10.1007/s11356-019-04249-4

Manuscript received: 22.04 .2019 